\title{
Use of Magnetic Nanoparticles as Targeted Therapy: Theranostic Approach to Treat and Diagnose Cancer
}

\author{
Arif Malik, ${ }^{1}$ Tariq Tahir Butt, ${ }^{2}$ Sara Zahid, ${ }^{3}$ Fatima Zahid, ${ }^{3}$ Sulayman Waquar, ${ }^{1}$ \\ Mahmood Rasool, ${ }^{4}$ Mahmood Husain Qazi, ${ }^{5}$ and Aamer Mahmood Qazi ${ }^{5}$ \\ ${ }^{1}$ Institute of Molecular Biology and Biotechnology (IMBB), The University of Lahore, Lahore, Pakistan \\ ${ }^{2}$ Department of Biochemistry, Khawaja Muhammad Safdar Medical College, Sialkot, Pakistan \\ ${ }^{3}$ Faculty of Pharmacy, The University of Lahore, Lahore, Pakistan \\ ${ }^{4}$ Center of Excellence in Genomic Medicine Research (CEGMR), King Abdulaziz University, Jeddah, Saudi Arabia \\ ${ }^{5}$ Centre for Research in Molecular Medicine (CRiMM), The University of Lahore, Lahore, Pakistan
}

Correspondence should be addressed to Arif Malik; arifuaf@yahoo.com

Received 23 February 2017; Accepted 18 April 2017; Published 30 May 2017

Academic Editor: Liwen Li

Copyright (C) 2017 Arif Malik et al. This is an open access article distributed under the Creative Commons Attribution License, which permits unrestricted use, distribution, and reproduction in any medium, provided the original work is properly cited.

\begin{abstract}
The metastasis of cancer epitomizes the diagnostic and therapeutic challenge as a result of cancer heterogeneity. To overcome the uncontrolled growth of the proliferating cells, nanosystems have been developed and have undergone many preclinical trials both in vitro and in vivo and many practices have been further applied clinically on human beings. In practice, magnetic nanoparticles(MNPs-) based systems following the application of $\mathrm{Fe}_{3} \mathrm{O}_{4}$ bound antitumor drug have shown an enhanced therapeutic index in comparison with conventional chemotherapy ensuring the significant decline in nanosystems' toxicity. A number of improved strategies employing nanoparticle engineering have been in practice for upgrading selectivity of metastatic cells and to have direct access to poorly manageable tumor regions. Targeted nanoparticle therapy paving the way towards tumor biomarkers and tissue specific cancer stages provides effective strategies for nonaccessible tumor regions, thus leading to the tangible modification in the history of cancer world. An infinite number of targets have been exploited for surface receptor specificity to distinct types of nanoparticles and are presently enduring clinical practices both in vitro and in vivo. The aim of this review is to take into view current nanotechnology-based research in cancer imaging for diagnosis and treatment. Several commercially available magnetic nanoparticles-based systems applied as contrast agents for metastatic cancer imaging and treatment via hyperthermia have also been focused on.
\end{abstract}

\section{Introduction}

1.1. Cancer: The Delinquent for Human. Human cancer is a highly incomprehensible devastating malaise developed through multistep cellular physiological and molecular cascades entailing cell signaling, apoptosis, and genetic instability. The development of cancer is not localized to the specified organ but it can also affect the distant areas within the body, which is called metastatic condition. Currently available diagnostic and prognostic biomarkers do not reflect the entire medical heterogeneity of tumors, which makes the cancer incorrigible [1]. At present, cancer patients are treated based on their clinical pathology and staging, which is determined by progressive diagnostic implements including histopathological examinations and tissue biopsy. The most widely used cancer treatments to date are chemotherapy, conventional radiology, and surgery. In spite of that, the early diagnosis and recognition of the cancerous condition are a technological bottleneck overwhelmed by some shortcomings [2]. For example, more than $60 \%$ of the breast, colon, lung, prostate, and ovarian tumor patients present hidden clinical presentation or show obvious metastatic mass production. The most encountered clinical challenges by the current cancer theranostic approaches are random bioavailability of the anticancer agents in the body, nonspecific drug approach towards the tumor site, cytotoxicity intolerability, 
and multidrug resistance. The successful diagnosis and treatment of cancer are based upon the development of innovative technologies that aid in the demarcation of tumor cells, identify the stage of metastasis, and confirm that the existence of tumor has been completely wiped out [3].

\subsection{Application of Nanotechnology in Cancer Therapeutics.} Cancer nanotechnology is a new path towards the advancement in oncodetection, tumor targeting, diagnosis, and treatment to fight the dilemma of cancer in human beings. The main rationale of designing this technology is based upon the specific optical, electromagnetic, and electrostructural assets which are not amiable with ordinary bulk molecules [4]. The nature of nanoparticles is based upon metal, semiconductor, and polymeric particles which make covalent bonds with biological molecules including functional peptides, nucleic acids, and minute ligand compounds. They bind to specific receptors on the plasma membrane intracellularly or extracellularly and signal the respective cascades to recognize the responsible genes and causative agents of cancer and promote the way of the defected genes to the genetic correction through transcription and translation of apoptotic genes. Therefore, nanotechnology has progressed a lot in the present era to eliminate ruthless oncobehaviour and promote the successful prognosis in the patients for clinical outcome [5]. The analytic biomolecules related to cancerous cells help in the detection of the tumor site and the existence of tumor and are hence called cancer biomarkers. They may be any transformed genes, mutant molecules, microRNAs, proteins, conjugated carbohydrates, or changes in genetic expressions that are superficially involved with tumor molecular profiling behaviour and its clinical outcome. The correlation of oncogenes and their molecular signature recognizes the genetic profiling of the specific cancer type. For example, in case of colon, breast, prostate, and liver cancers, the lethal behaviours of bone metastasis, radiation, and hormone-independent and chemotherapy-resistant genotypes in addition to phenotypes were widely indicated. The interrelationship of biomarkers with molecular signature of oncogenes provides the possible pathways of envisaging of the progression of cancer and its clinical outcome called prognosis. Therefore, preclinical trials employing cancer nanotechnology are undergoing in experimental animal models in research laboratories for the successful implication of nanotechnology in human beings for prediction of cancer stage and its treatment [6].

1.3. Nanotechnology Solicitation in Preclinical Trials. The whole process of moving cancer nanotechnology from application to clinical trials took approximately 10 to 12 years. Before a drug is undergone for a clinical trial, it has to face a lot of preclinical trials. The preclinical trial phases especially focus on the toxicity, pharmaceutics, pharmacodynamics, and safety profile of the drug under study. The effect of wide range of drug doses is tested by in vitro (preparing cell lines of cancer verses normal cell lines) and in vivo (animals such as rats or rabbits) experimentation. As shown in Figure 1, preclinical studies are also carried out using computer-based bioinformatic software of the drug target profiling including toxicological studies. The goal of the preclinical trials is to move the nanotechnology from the preliminary stage to the clinical phase [7].

\subsection{Preclinical Biocompatibility Evaluation of Magnetic Nanoparticles (MNPs) of Medical Importance. The} biocompatibility of magnetic nanosystems of cancer therapeutics such as $\mathrm{Fe}_{3} \mathrm{O}_{4}$ nanoparticles is achieved due to its intense heating capability which is produced from an outer alternate magnetic field (AMF) source. This ability makes it able to be extensively used in medical imaging systems, magnetic hyperthermia systems in tumor diagnosis and treatment, and controlled drug delivery systems of nanocarriers [8]. The biocompatibility of nanoparticles which are used for cancer treatment is tested through a preclinical succession of biological tests initiating from in vitro preclinical tests using cancer cell lines (e.g., HepG2 for liver cancer) in comparison with normal cell lines (e.g., Vero cell lines) which proceeds towards in vitro testing using experimental animal models (such as albino mice, albino Wistar rats, or rabbits) and is then eventually applied on human beings for further clinical trials. This sequence of phases, that is, from preclinical phase to clinical phase, followed by relevant experiments allows the respective nanoparticles to be used for the treatment of cancer [9].

1.4.1. Preclinical In Vitro Biological Evaluation. The procedure of in vitro testing is based upon the idea of conducting experiments using a meticulous medium in animal model just similar to the meticulous medium present in the human beings despite of the physiological complexity that can prove the effect of the respective nanoparticle for the treatment of cancer using different cancer cell lines. The benefits of in vitro evaluation over in vivo method include a number of aspects [10]. The complexity of the cell lines is much lower as compared to the animal model and the cellular models are easier to apprehend as compared to the in vivo model. In addition, there would be much less cost using in vivo cell cultures providing prompt information in lesser time. The norm of in vitro testing assures the decline of experimental animals' sacrifice and preclinical tests are considered successful only after the constructive results of in vitro testing. The monolayer of the adherent parent cells is preferably cultured with the exception of hematopoietic stem cells being cultured in suspension [11]. Preferably, the biological effects of different materials such as nanoparticles on cancer cells are evaluated using commercially available immortalized cells because of their unique property of rapid production, sustainability, and the easy outcome of the results. The more accurate results avoiding any impurities are obtained using primary cell cultures which exhibit properties $90 \%$ similar to those provided by in vivo model [12].

1.4.2. Preclinical In Vivo Biological Evaluation. Preclinical evaluation is an important step preceding the clinical trials which gives better evaluation of the biocompatibility of the nanoparticles due to direct relation with body of the animal. The authenticity of in vivo modelling is achieved by selecting a suitable experimental animal model [13]. Widely used experimental animals for nanoparticles testing 

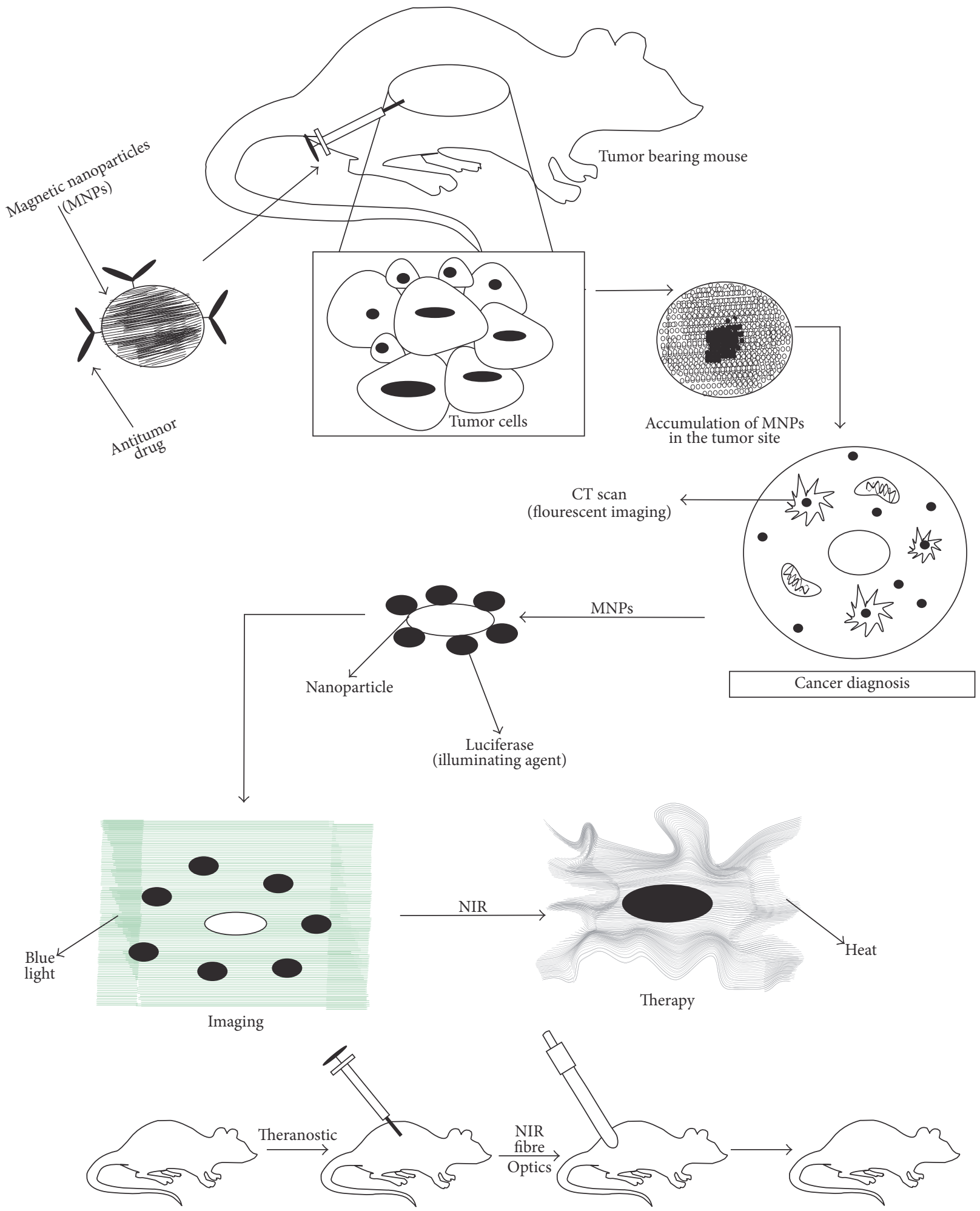

FIGURE 1: Schematic illustration of diagnosis by magnetic nanoparticles-guided cancer therapy. The recognition of tumor cells is conjugated with hyperthermic nanoparticles and inserted in vivo. In albino C57BL/6 mice, by intraperitoneal injection, our theranostic approach is able to recognize the accumulated nanoparticles at the tumor region causing significant infiltration of T-cells and macrophages creating angiogenesis process in the tumor cells causing a decline in tumor dimensions. The apoptotic rate is improved and optimal treatment is obtained in vivo in the albino rat model which is treated with MNPs through the mediation of illuminating agent. 
are albino mouse strains (BALB/c and C57BL/6), albino Wistar rat strains (Sprague Dawley rats, Fischer 344), swine, zebrafish (for vertebrate animal model), Daphnia magna (for invertebrate model), and chick embryo (for embryogenesis study). However, the in vivo testing provides the results after considerably a long period of time when animal shows the effect of the respective nanoparticle morphologically or anatomically with complex interpretation and greater cost [14]. Clinical in vivo biological evaluation is also carried out on human subjects but these clinical trials are made only after the productive results obtained from the preclinical experimentation either in vivo or in vitro. The clinical tests on human beings are restricted in many countries of the world due to bioethical issues; therefore, only volunteers are being susceptible to the clinical trials [15].

1.5. Preclinical In Vivo Testing of Iron Oxide Magnetic Nanoparticles $\left(\mathrm{Fe}_{3} \mathrm{O}_{4}\right.$ MNPs) for Oncological Diagnostics. Maximum in vivo preclinical studies of $\mathrm{Fe}_{3} \mathrm{O}_{4}$ MNPs are conducted to check their functional prospective with some contrast materials. The effective magnetic resonance imaging (MRI) uses contrast imaging system to diagnose the existence of abrupt cellular mass production in the tissue [16]. The principle of magnetic resonance imaging is the vast dissimilarity between magnetic slackening of water protons in solution of nanoparticles and surrounding tissues called longitudinal relaxation-spin lattice which dominate the bright regions of the image and the transversal decrease: spin-spin determines the dark regions of the specified image. The difference between the two independent slackening processes creates the contrast image from the background. The coefficient of relaxivity $\left(\mathrm{mM}^{-1} \mathrm{~s}^{-1}\right)$ measures the efficiency of the contrast agent determining a well-defined image [17]. In 2014, Li et al. researched on improving the MRI imaging technique and developed a technique by using poly(ethylene glycol)-poly(aspartic acid) (PEG-PAsp) $\mathrm{Fe}_{3} \mathrm{O}_{4}$ nanoparticles which were administered intraperitoneally in the body of cancer patient and then transforming growth factor (TGF- $\beta$ ) inhibitor was introduced intraperitoneally [18]. The commercial dextran $\mathrm{Fe}_{3} \mathrm{O}_{4}$ MNPs (Resovist) were used as standard. The behaviour of these nanoparticles was anomalous. The $\mathrm{Fe}_{3} \mathrm{O}_{4}$ nanoparticles showed their effect after 24 hours of the TGF- $\beta$ inhibitor administration as demonstrated by the MRI images. It meant that designed $\mathrm{Fe}_{3} \mathrm{O}_{4}$ nanoparticles accumulated in the cancerous tissues after the period of two hours of treatment. The histopathological findings also confirmed the accumulation of $\mathrm{Fe}_{3} \mathrm{O}_{4}$ nanoparticles in the tumor regions in comparison with MRI images [19].

In 2013, Lv et al. researched on the pharmacodynamics of the superparamagnetic iron oxide nanoparticles (SPIONs) and ultrasuperparamagnetic iron oxide nanoparticles (Dextran shell) carrying MRI. 36 Swiss albino C57BL/6 mice were given intraperitoneally the carcinogenic agent and were induced with tumor of the first stage. These albino mice have then undergone magnetic resonance imaging (MRI) of the above said nanoparticles. The different harvested organs were then ultrastained with Prussian Blue stain and the presence of Fe particles was determined. It was observed that the main target organ with accumulated Fe particles being liver was seen to be much larger approximately three times in mice injected intraperitoneally with USPIONs as compared to the mice injected with SPIONs [20]. The research also reported the fact that the main accumulation area of USPIONs was liver parenchyma cells, whereas lymphatic nodules showed the accumulation of both USPIONs and SPIONs in equal proportions. Therefore, it is recommended that, for imaging liver tumor, USPION mediated MRI should be applied and, for mediastinal lymph nodes, both USPIONs and SPIONs mediated MRI can be useful [17]. A 2014 research report by $\mathrm{Li}$ et al. described the astonishing behaviour of iron oxide nanoparticles in MRI for cancer diagnosis. 100 albino Wistar rats were injected intraperitoneally with iron oxide nanoparticles at the concentration of $100 \mu \mathrm{mol}$. The blood samples of all the rats were analysed after 360 minutes of administration. The relaxation time was measured by relaxivity $\mathrm{rl}$ and $\mathrm{r} 2$. The MRI analysis was carried out for these albino mice with injected cancer after every 3 minutes which was recorded after 2 hours and 3 minutes of the intraperitoneal injection. The research work presented quite successful results. The blood half-time was elevated when dose was administered and reduced when magnetic nanoparticles with high dimensions were injected. This meant that magnetic iron oxide nanoparticles possess good bioavailability in the biological system and provide good imaging with contrast agents as compared to the other imaging agents used in MRI [18].

Other current researches also confirmed the in vivo efficiency of these iron oxide magnetic nanoparticles. In $\mathrm{BALB} / \mathrm{c}$ mice with injected solid pancreatic tumors, contrast imaging was done using poly(ethylene glycol)-poly(aspartic acid) iron oxide nanoparticle [19]. Swine of $35-70 \mathrm{~kg}$ were diagnosed with head and neck cancer through citrate $\mathrm{Fe}_{3} \mathrm{O}_{4}$ nanoparticles MRI. Wistar albino mice with hepatocellular carcinoma were diagnosed successfully using $\mathrm{Fe}_{3}-\mathrm{O}_{4}-\mathrm{NH}_{2}$ $\mathrm{AF}$ (folic acid) at concentration of $3 \mathrm{mg} / \mathrm{kg}$ body weight. Nude mice with infected oral epidermoid tumor tissue displayed improved darkening capacity and tumor specificity of $\mathrm{Fe}_{3} \mathrm{O}_{4}$-CMD mediated MRI scan [30]. Similarly, for prostate cancerous $\mathrm{BALB} / \mathrm{c}$ nude mice, the MRI with application of SCAB (prostate cancer stem cells antibody)PLGA-SPIO/Docetaxel was compared before and after the treatment and acquired good diagnosis of prostate cancer. Magnetic nanoparticles $\mathrm{HA}_{31 \mathrm{k}}$ were used to diagnose cervical cancer in albino rats using U87MG model of MRI scan which provided better comparison results [31]. The presence of glioblastoma cells in rats was also detected using $\mathrm{Fe}_{3}$ $\mathrm{O}_{4}$-PEI- (polyethylene imine-) HA- (hyaluronic acid-) F1 (fluorescein isothiocyanate) MNPs with efficient targeting of the cancerous cells [32].

1.6. Preclinical In Vivo Testing of $\mathrm{Fe}_{3} \mathrm{O}_{4}$ MNPs Using Magnetic Hyperthermia for Oncological Treatment. The technique of magnetic hyperthermia-based nanoparticles is constructed on the principle that the temperature of the local tissue is raised to approximately $41-43^{\circ} \mathrm{C}$ with the help of fluctuating magnetic field for a specified period of time just like hysteresis loss and Brownian relaxation principle. The energy gained from the applied magnetic field is incorporated in 


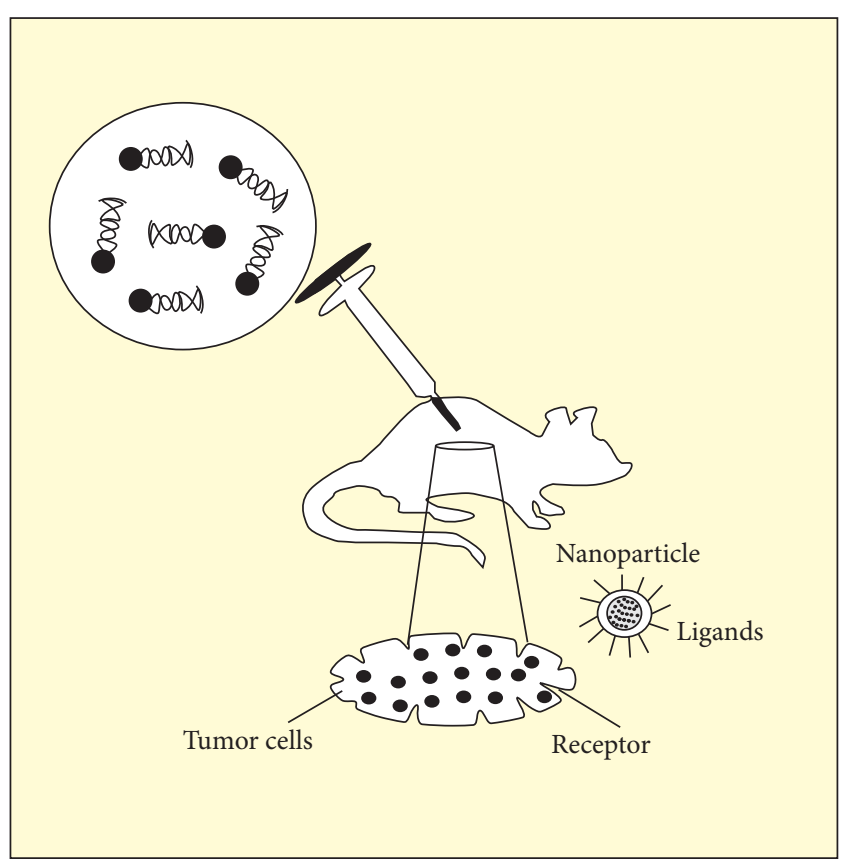

FIGURE 2: The mechanism of active tumor targeting of magnetic nanoparticles. The active tumor targeting of nanoparticles has been in practice in current era in albino mice. The ligands are attached to the outer surface of nanoparticles. The desired anticancer drug is attached to the outer surface of the site specific nanoparticles which recognize and ensure the efficient entry of the drug to the tumor cell reducing the toxicity in the neighbouring normal cells.

the nanoparticles and is being converted to thermal energy with the aid of specified absorption rate (SAR) parameter which measures the continuous conversion of this magnetic energy into thermal energy. The nanoparticles are mounted up in the cancerous tissues both by passive targeting and by active targeting [28]. Active targeting is achieved by magnetic field application due to the functional specificity of different agents including folic acid and passive targeting is associated with enhanced retention time of nanoparticles inside the tumor tissues and increased permeability effect (Figure 2). The use of magnetic nanoparticles increases the temperature sensitivity of the tumor tissues reaching up to $41-43^{\circ} \mathrm{C}$ but for some magnetic nanoparticles reaching up to $46-47^{\circ} \mathrm{C}$ as compared to healthy tissues, which gives a differential contrast of the nanoparticles accumulated regions by magnetic hyperthermia. The most favourable AMF applied for magnetic hyperthermia must reside under the value of $5 \times$ $10^{9} \mathrm{Am}^{-1} \mathrm{~s}^{-1}$ and $1 \mathrm{MHz}$ frequency to avoid any disastrous side effects [33].

1.7. In Vivo Preclinical Trials of Magnetic Nanoparticles in Comparison with Chemotherapy. Chemotherapy is the most common method used in the treatment of cancer. It is practical fact that when numerous distinct antitumor agents are introduced in a large quantity, the whole body is exposed to these therapeutic molecules. The reported adverse effects of chemotherapeutic molecules mainly include hepatotoxicity, cardiac failures, depression, and nephrotoxicity [31].
A research study conducted on the comparison of using chemotherapeutic substances and magnetic nanoparticles exposes the positive effects of magnetic nanoparticles as cancer therapeutics in contrast with chemotherapy technique. 16 female albino C57BL/6 mice injected with pancreatic cancer were divided into different groups. A control group was injected with saline PBS buffer and other groups were injected with DMSA-MNPs at the concentration of $300 \mu \mathrm{g}$ Fe/injection and one group received intraperitoneally IFN- $Y$ DMSA-MNPs at 10,000 U IFN- $\Upsilon+300 \mu \mathrm{g}$ Fe/injection when tumor reached its volume of $200 \mathrm{~mm}^{3}$. The AMF applied was around $0.4 \mathrm{~T}$ for one hour. The treatment went for a period of two weeks (two times per week). The accumulation efficiency of DMSA-MNPs at the target tumor region and the delivery efficiency of IFN- $\Upsilon$ were evaluated. The results indicated high rate of accumulation of IFN-Y-DMSA-MNPs at the regions of tumor, which means that MNPs caused significant infiltration of T-cells and macrophages creating angiogenic process in the tumor cells causing a decline in tumor dimensions [34].

Another in vivo effect of Daunorubicin- (DNR-) $\mathrm{Fe}_{3} \mathrm{O}_{4}$ MNPs on nude mice suffering from leukemia cells K562 (Adriamycin resistant leukemia cells KA) compared with healthy control mice also confirmed the clinical efficacy of $\mathrm{Fe}_{3} \mathrm{O}_{4}$ MNPs in diagnosis and treatment of leukemia (blood cancer). A dramatic decrease in tumor growth and upregulation of apoptotic expression was observed in leukemic mice treated with $\mathrm{Fe}_{3} \mathrm{O}_{4}$ MNPs. Some of the commercially available MNPs are described in Table 1. A study conducted on the treatment of sarcoma cancer was developed using magnetic nanoparticles in comparison with Doxorubicin (DOX) which is a system based on $\mathrm{Fe}_{3} \mathrm{O}_{4}$-CA- (citric acid-) chitosan encapsulated with polymeric microspheres (PLGA). 28 albino rats were intraperitoneally infected with sarcoma cells S-180 at the concentration of $2 \times 10^{6}$ cells $/ 0.2 \mathrm{ml}$. These rats were exposed to magnetic nanoparticles mediated MRI scan by exposing the tumor site to AMF for three hours for better targeting. A laser beam of $1 \mathrm{~cm}$ diameter was focused for 15 minutes to trigger the biodistribution and accumulation. The imaging scan demonstrated clearly that the injected MNPs were accumulated at the tumor site which actively showed the existence of tumor and the downregulation of the tumor promoting growth factors. Also, the size of the tumor was also seen to be reduced and the side effects of the sarcoma cancer, that is, cardiotoxicity, were also observed to be successfully eliminated [35]. A research team worked on the diagnosis and treatment of hepatocellular carcinoma by utilizing Hepatoma cells $\mathrm{H} 22(0.2 \mathrm{ml}$ with the concentration of $10^{7}$ cells $/ \mathrm{ml}$ ) in vivo in Kunming mice model of liver injury. Ten Kunming mice were injected with Dimethylnitrosamine at $1 \mathrm{ml} / \mathrm{kg}$ body weight at alternate days for four weeks, which develops hepatocellular carcinoma checked by biopsy. Then these mice were subcutaneously injected with antitumor drug Evodiamine through MPEGPLGA delivery system. The obtained results were astonishing with the 50\% tumor suppression upon MPEG-PLGASPIONs-Evodiamine treatment as compared to the mice treated with saline solution of Evodiamine. The apoptotic rate was also improved and the optimal treatment was observed 
TABLE 1: Summary of the commercially available nanosystems as contrast agents for preclinical and clinical trials.

\begin{tabular}{|c|c|c|c|c|c|}
\hline $\begin{array}{l}\text { Commercial magnetic } \\
\text { nanoparticles }\end{array}$ & Target regions & Size & Receptor & $\begin{array}{c}\text { Biocompatibility and } \\
\text { toxicity evaluation }\end{array}$ & References \\
\hline $\mathrm{Fe}_{3} \mathrm{O}_{4}$-SPIONs & $\begin{array}{l}\text { Metastatic } \\
\text { hepatocytes }\end{array}$ & $30-34 \mathrm{~nm}$ & HepG2 & $\begin{array}{c}\text { Magnetic resonance } \\
\text { hyperthermia for imaging } \\
\text { cardiotoxicity }\end{array}$ & {$[20,21]$} \\
\hline Polymeric nanoparticles & $\begin{array}{l}\text { Osteopontin (OPN) } \\
\text { and bone resorption }\end{array}$ & $180-200 \mathrm{~nm}$ & $\begin{array}{l}\text { Clotted plasma } \\
\text { protein }\end{array}$ & In vitro cytotoxicity & [22] \\
\hline $\begin{array}{l}\text { Liposomes } \\
\text { (Doxorubicin) }\end{array}$ & $\begin{array}{l}\text { Tumor cell surface } \\
\text { bound molecules }\end{array}$ & $112 \mathrm{~nm}$ & P32 & $\begin{array}{l}\text { In vivo evaluation of } \\
\text { erythrocyte vascularization }\end{array}$ & {$[23]$} \\
\hline Silicon nanoparticles & Bone osteoblasts & $1.6 \pm 0.1 \mu \mathrm{m}$ & E-selectin & $\begin{array}{c}\text { In vitro and in vivo } \\
\text { evaluation of bone } \\
\text { physiology }\end{array}$ & {$[18,24]$} \\
\hline Dendrimers & Albumin protein & $141-150 \mathrm{~nm}$ & Y1 receptor & $\begin{array}{l}\text { Systemic and pulmonary } \\
\text { cytotoxicity }\end{array}$ & {$[25]$} \\
\hline Paclitaxel & $\begin{array}{l}\text { Albumin bound } \\
\text { proteins }(\mathrm{Nab})\end{array}$ & $130-150 \mathrm{~nm}$ & $\begin{array}{l}\text { Estrogen receptor } \\
\text { (ER) }\end{array}$ & In vitro cytotoxicity & {$[26]$} \\
\hline Orlistat $\left(\mathrm{Fe}_{3} \mathrm{O}_{4}-\mathrm{NH}-\mathrm{AF}\right)$ & $\begin{array}{c}\text { Micellar cells } \\
\text { functionalised with } \\
\text { folic acid }\end{array}$ & $100-200 \mathrm{~nm}$ & Folate receptor & $\begin{array}{l}\text { In vivo evaluation of liver, } \\
\text { spleen, and nephrotoxicity }\end{array}$ & [27] \\
\hline Anti-miR-10b MNPs & $\begin{array}{c}\text { Targeted antisense } \\
\text { loaded PLGA-b-PEG } \\
\text { polymer } \\
\text { nanoparticles }\end{array}$ & $50-100 \mathrm{~nm}$ & uPA receptor & $\begin{array}{l}\text { In vivo evaluation of liver } \\
\text { and kidney and in vitro } \\
\text { evaluation of cytotoxicity }\end{array}$ & {$[28]$} \\
\hline Dextran $\left(\mathrm{Fe}_{3} \mathrm{O}_{4}\right)$ & $\begin{array}{l}\text { Liver, lymph nodes, } \\
\text { and spleen }\end{array}$ & $20-50 \mathrm{~nm}$ & $\begin{array}{c}\text { Tumour cell bounded } \\
\text { nucleosomes }\end{array}$ & $\begin{array}{c}\text { Polymeric in vivo } \\
\text { nanoimaging }\end{array}$ & {$[29]$} \\
\hline
\end{tabular}

in vivo in mice treated with MNP mediated MPEG-PLGASPIONs-Evodiamine system compared with antitumor drug Cyclophosphamide (positive control). These results are in complete agreement that magnetic nanoparticles are the best option for the successful diagnosis of the existence of tumor as well as the treatment through the tumor suppression [36].

1.8. Conclusion. The conventional method of diagnosis and treatment of local as well as metastatic tumor is biopsy followed by chemotherapy which is very painful for the patient and time-taking. Also there are certain limitations regarding chemotherapy to achieve the reduction of tumor. In spite of that, the complete removal of the tumor is not achieved with chemotherapy. Therefore, the satisfactory detection and cure of the metastatic cancer still remain a key challenge. This difficulty prones the scientists and researchers to work on nanoparticles for the diagnosis and treatment of the tumor using nanoformulated anthracyclines and paclitaxel. The active targeting of the tumor has been achieved using magnetic nanoparticles in vivo using albino mice and rats as preclinical and basic trials for further application on human subjects. Specific ligands and antitumor drugs have been conjugated on the surface of the nanoparticles which successfully interact with tumor proliferating cells causing accumulation at the tumor sites. The contrast agents are used to show brighter images through MRI scan. The regions where nanoparticles are accumulated appear brighter, confirming a satisfactory diagnostic evidence of the existence of the tumor cells. These active targeting nanostrategies provide reduced cytotoxicity and chemoresistance and promote the expression of apoptotic factors. Concluding the whole study, it is believed that magnetic nanoparticles are not toxic at a very low concentration and their elimination from the biological system can be made possible by standard metabolic cascades. Therefore, the targeting system and antitumor activity of nanoparticles-based systems are valid and efficient for improved diagnosis and treatment of cancer as depicted by many preclinical trials.

\section{Future Prospects}

The magnetic nanoparticles-based biomedical applications have undergone many preclinical trials for biological evaluation and application on the human biological system. Despite the fact that many aspects regarding these nanosystems have been cleared, still there are many insecurities regarding nanoparticles biocompatibility. These insecurities include the fact that these nanoparticles are very minute in size but are used in larger quantities for proper accumulation at the tumor site due to which it is difficult for the biological systems to eliminate these nanoparticles from the metabolism. In addition, the induction of nanoparticles stimulates the cascade of production of reactive oxygen species (ROS), which deteriorate the mitochondrial functioning and damage DNA, which results in numerous neurodegenerative diseases. Moreover, the accumulation of nanoparticles in various organs like liver, kidney, lungs, and spleen brings about histopathological modifications and remote body reactions. But, in the recent era, the controversial effects of several imaging techniques based on nanoparticles such as MRI, 
chemotherapy, and magnetic hyperthermia can be controlled by human body self-defense system. The above-mentioned disadvantages of the nanosystems can also be avoided by using biocompatible polymers and encapsulating surfactants to cross the barriers of the human body improving the biocompatibility of the nanosystems. Nevertheless, active collaboration among researchers and nanotechnologists can provide strong progress to achieve clinical revolution in the world of cancer.

\section{Conflicts of Interest}

The authors declare that there are no conflicts of interest.

\section{Acknowledgments}

The authors are highly thankful to Professor Dr. M. H. Qazi, Center for Research in Molecular Medicine (CRiMM), for providing the innovative and financial support for the project.

\section{References}

[1] Q. L. Jiang, S. W. Zheng, R. Y. Hong et al., "Folic acid conjugated $\mathrm{Fe} 3 \mathrm{O} 4$ magnetic nanoparticles for hyperthermia and MRI in vitro and in vivo," Applied Surface Science, vol. 307, pp. 224-233, 2014.

[2] A. C. Powell, G. F. Paciotti, and S. K. Libutti, "Colloidal gold: a novel nanoparticle for targeted cancer therapeutics," Methods in Molecular Biology (Clifton, N. J.), vol. 624, pp. 375-384, 2010.

[3] A. S. Wadajkar, Z. Bhavsar, C.-Y. Ko et al., "Multifunctional particles for melanoma-targeted drug delivery," Acta Biomaterialia, vol. 8, no. 8, pp. 2996-3004, 2012.

[4] A. Jemal, R. Siegel, J. Xu, and E. Ward, "Cancer statistics, 2010," CA Cancer Journal for Clinicians, vol. 60, no. 5, pp. 277-300, 2010.

[5] B. A. J. Ponder, "Cancer genetics," Nature, vol. 411, no. 6835, pp. 336-341, 2001.

[6] C. Minelli, S. B. Lowe, and M. M. Stevens, "Engineering nanocomposite materials for cancer therapy," Small, vol. 6, no. 21, pp. 2336-2357, 2010.

[7] B. Quinn, "Preparation and maintenance of live tissues and primary cultures for toxicity studies," in Biochemical Ecotoxicology: Principles and Methods, Chapter 3, pp. 33-47, Academic Press, Oxford, UK, 2014.

[8] C.-J. Zhou, S.-H. Wang, Y. Zhou et al., "Folate-conjugated $\mathrm{Fe} 3 \mathrm{O} 4$ nanoparticles for in vivo tumor labeling," Transactions of Nonferrous Metals Society of China (English Edition), vol. 23, no. 7, pp. 2079-2084, 2013.

[9] J. Baumann, J. Köser, D. Arndt, and J. Filser, "The coating makes the difference: acute effects of iron oxide nanoparticles on Daphnia magna," Science of the Total Environment, vol. 484, no. 1, pp. 176-184, 2014.

[10] E. Porcel, S. Liehn, H. Remita et al., "Platinum nanoparticles: a promising material for future cancer therapy?" Nanotechnology, vol. 21, no. 8, Article ID 085103, 2010.

[11] D. E. Mihaiescu, A. S. Buteicǎ, J. Neamţu, D. Istrati, and I. Mîndrilă, "Fe3O4/Salicylic acid nanoparticles behavior on chick CAM vasculature," Journal of Nanoparticle Research, vol. 15 , no. 8 , article $1857,2013$.
[12] K. G. Stevens, "The clinical evaluation and approval threshold of biomaterials and medical devices," in Regulatory Affairs for Biomaterials and Medical Devices, Chapter 5, pp. 67-77, Woodhead Publishing Ltd., Cambridge, UK, 2014.

[13] H. Chen, L. Shao, T. Ming et al., "Understanding the photothermal conversion efficiency of gold nanocrystals," Small, vol. 6, no. 20, pp. 2272-2280, 2010.

[14] J. Xie, S. Lee, and X. Chen, "Nanoparticle-based theranostic agents," Advanced Drug Delivery Reviews, vol. 62, no. 11, pp. 1064-1079, 2010.

[15] J. Zhang, Y. Fu, Y. Mei, F. Jiang, and J. R. Lakowicz, "Fluorescent metal nanoshell probe to detect single mirna in lung cancer cell," Analytical Chemistry, vol. 82, no. 11, pp. 4464-4471, 2010.

[16] X. L. Liu and H. M. Fan, "Innovative magnetic nanoparticle platform for magnetic resonance imaging and magnetic fluid hyperthermia applications," Current Opinion in Chemical Engineering, vol. 4, pp. 38-46, 2014.

[17] Y. Zhang, B. Zhang, F. Liu, J. Luo, and J. Bai, "In vivo tomographic imaging with fluorescence and MRI using tumortargeted dual-labeled nanoparticles," International Journal of Nanomedicine, vol. 9, no. 1, pp. 33-41, 2013.

[18] J. Li, Y. He, W. Sun et al., "Hyaluronic acid-modified hydrothermally synthesized iron oxide nanoparticles for targeted tumor MR imaging," Biomaterials, vol. 35, no. 11, pp. 3666-3677, 2014.

[19] A. E. Deatsch and B. A. Evans, "Heating efficiency in magnetic nanoparticle hyperthermia," Journal of Magnetism and Magnetic Materials, vol. 354, pp. 163-172, 2014.

[20] Y. Lv, G. Ding, J. Zhai, Y. Guo, G. Nie, and L. Xu, "A superparamagnetic Fe3O4-loaded polymeric nanocarrier for targeted delivery of evodiamine with enhanced antitumor efficacy," Colloids and Surfaces B: Biointerfaces, vol. 110, pp. 411-418, 2013.

[21] S. Bhattacharyya, R. A. Kudgus, R. Bhattacharya, and P. Mukherjee, "Inorganic nanoparticles in cancer therapy," Pharmaceutical Research, vol. 28, no. 2, pp. 237-259, 2011.

[22] T. K. Sau, A. L. Rogach, F. Jäckel, T. A. Klar, and J. Feldmann, "Properties and applications of colloidal nonspherical noble metal nanoparticles," Advanced Materials, vol. 22, no. 16, pp. 1805-1825, 2010

[23] T. Stuchinskaya, M. Moreno, M. J. Cook, D. R. Edwards, and D. A. Russell, "Targeted photodynamic therapy of breast cancer cells using antibody-phthalocyanine-gold nanoparticle conjugates," Photochemical and Photobiological Sciences, vol. 10, no. 5, pp. 822-831, 2011.

[24] V. Raji, J. Kumar, C. S. Rejiya, M. Vibin, V. N. Shenoi, and A. Abraham, "Selective photothermal efficiency of citrate capped gold nanoparticles for destruction of cancer cells," Experimental Cell Research, vol. 317, no. 14, pp. 2052-2058, 2011.

[25] W. Lu, A. K. Singh, S. A. Khan, D. Senapati, H. Yu, and P. C. Ray, "Gold nano-popcorn-based targeted diagnosis, nanotherapy treatment, and in situ monitoring of photothermal therapy response of prostate cancer cells using surface-enhanced raman spectroscopy," Journal of the American Chemical Society, vol. 132, no. 51, pp. 18103-18114, 2010.

[26] X. He, J. Gao, S. S. Gambhir, and Z. Cheng, "Near-infrared fluorescent nanoprobes for cancer molecular imaging: status and challenges," Trends in Molecular Medicine, vol. 16, no. 12, pp. 574-583, 2010.

[27] L. Fiandra, S. Mazzucchelli, C. De Palma et al., "Assessing the in vivo targeting efficiency of multifunctional nanoconstructs bearing antibody-derived ligands," ACS Nano, vol. 7, no. 7, pp. 6092-6102, 2013. 
[28] H. Chen, L. Wang, Q. Yu et al., "Anti-HER2 antibody and ScFvEGFR-conjugated antifouling magnetic iron oxide nanoparticles for targeting and magnetic resonance imaging of breast cancer," International Journal of Nanomedicine, vol. 8, pp. 3781-3794, 2013.

[29] I. Hilger and W. A. Kaiser, "Iron oxide-based nanostructures for MRI and magnetic hyperthermia," Nanomedicine, vol. 7, no. 9, pp. 1443-1459, 2012.

[30] R. Mejías, L. Gutiérrez, G. Salas et al., "Long term biotransformation and toxicity of dimercaptosuccinic acid-coated magnetic nanoparticles support their use in biomedical applications," Journal of Controlled Release, vol. 171, no. 2, pp. 225-233, 2013.

[31] S. Toraya-Brown, M. R. Sheen, J. R. Baird et al., "Phagocytes mediate targeting of iron oxide nanoparticles to tumors for cancer therapy,' Intergrative Biology, vol. 5, no. 1, pp. 159-171, 2013.

[32] P. Chandra, D. Das, and A. A. Abdelwahab, "Gold nanoparticles in molecular diagnostics and therapeutics," Digest Journal of Nanomaterials and Biostructures, vol. 5, no. 2, pp. 363-367, 2010.

[33] L. Shang, K. Nienhaus, and G. U. Nienhaus, "Engineered nanoparticles interacting with cells: size matters," Journal of Nanobiotechnology, vol. 12, no. 1, article 5, 2014.

[34] M. K. Yu, J. Park, and S. Jon, "Targeting strategies for multifunctional nanoparticles in cancer imaging and therapy," Theranostics, vol. 2, no. 1, pp. 3-44, 2012.

[35] F. M. Kievit, Z. R. Stephen, O. Veiseh et al., "Targeting of primary breast cancers and metastases in a transgenic mouse model using rationally designed multifunctional SPIONs," ACS Nano, vol. 6, no. 3, pp. 2591-2601, 2012.

[36] R. A. Sperling and W. J. Parak, "Surface modification, functionalization and bioconjugation of colloidal Inorganic nanoparticles," Philosophical Transactions of the Royal Society A: Mathematical, Physical and Engineering Sciences, vol. 368, no. 1915, pp. 1333-1383, 2010. 

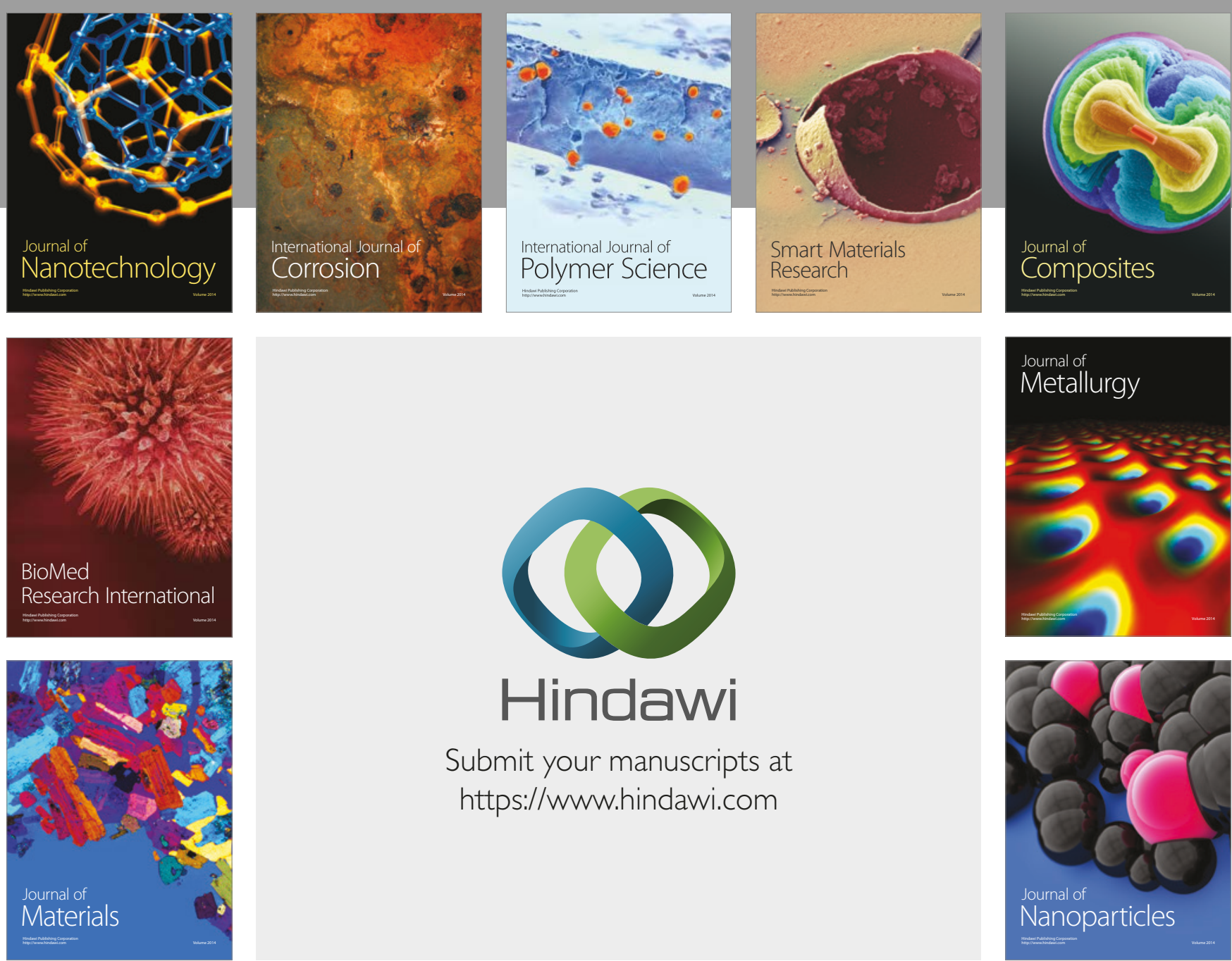

\section{Hindawi}

Submit your manuscripts at

https://www.hindawi.com
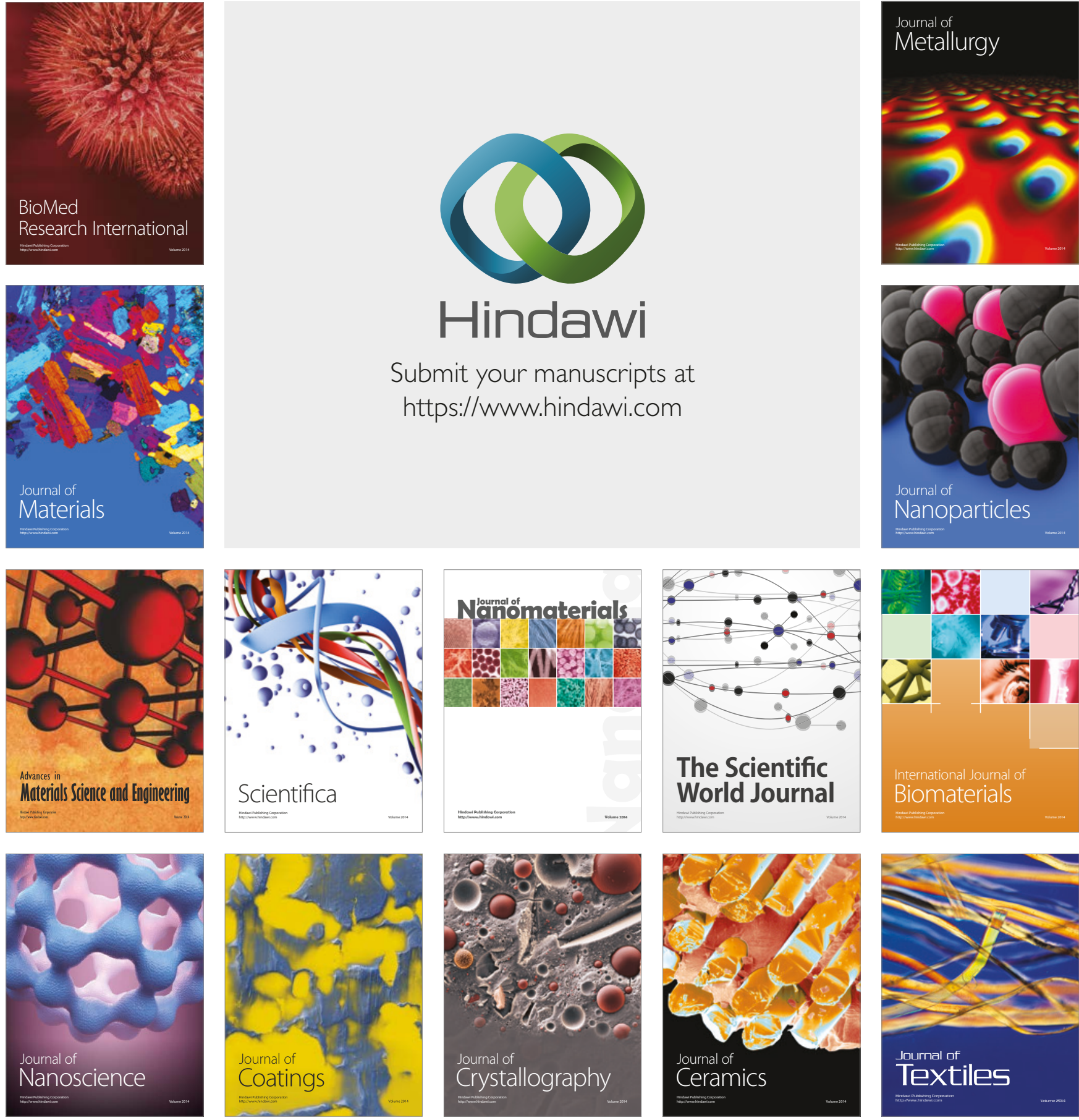

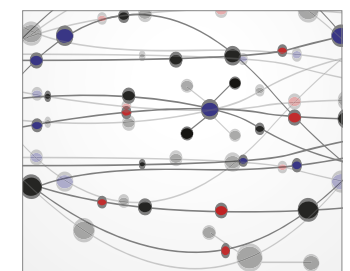

The Scientific World Journal
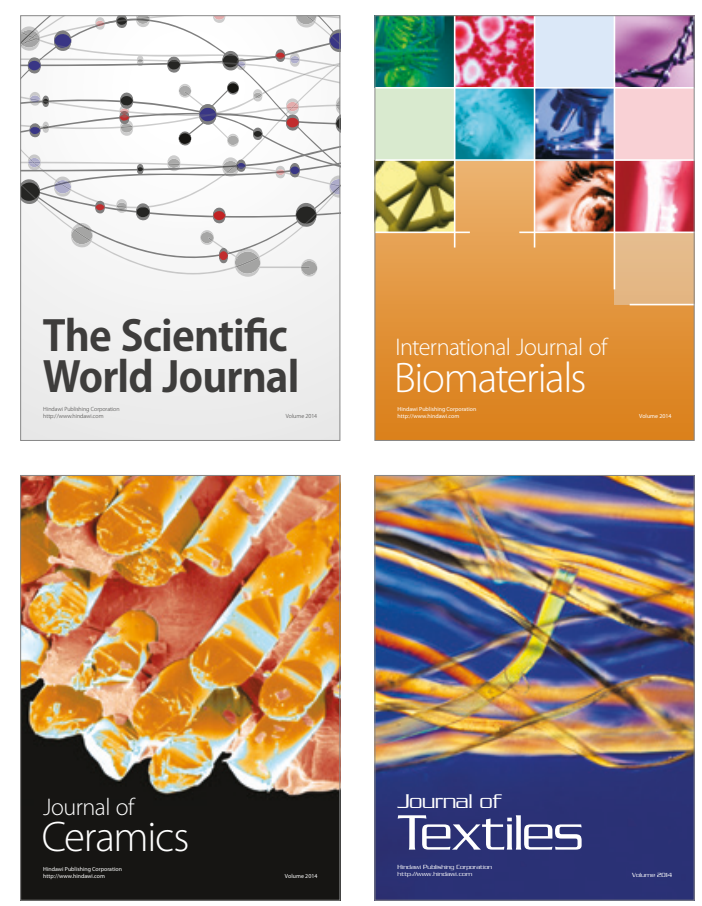